\title{
Relationship between family functions with depression in palliative patients
}

\author{
Johan Kurniawan!, \\ Ni Ketut Putri Aryani², \\ Ida Ayu Kusuma Wardani2
}

'Department of Psychiatry, Natalia Boyolali General Hospital, Central Java, Indonesia

${ }^{2}$ Department of Psychiatry, Sanglah General Hospital, Bali, Indonesia
Cite this article:

Kurniawan J, Aryani NKP. Relationship between family functions with depression in palliative patients. Journal of Clinical and Cultural Psychiatry. 202 I;2(I): I-3. DOI: I0.36444/jccp.v2il.I7
Corresponding author: dr. Ni Ketut Putri Aryani, SpKJ. Department of Psychiatry Sanglah General Hospital Jl. Kesehatan I, Denpasar 80II4 Bali, Indonesia

Email: putriaryani@unud.ac.id

\begin{abstract}
Background: Diseases or health problems are a part of life that can occur at any time. Terminal disease represents a patient's irreversible health condition, so that this group of patients can be given a therapeutic approach known as palliative care. Patients who experience significant conflict in the family can increase the likelihood of depression.

Patients and Methods: This is a descriptive cross-sectional study in 32 subjects chosen by consecutive sampling. Measuring instrument used was Beck's Depression Inventory. The family function scale is derived from the McCaster's Model of Family Functioning known as the Family Assessment Device (FAD).

Results: In this study, the average age of the sample was 46 years, unmarried from high school education. In the description of family functions obtained with overall results with moderate function. Correlation between the two things was found to be a weak negative correlation between FAD score and BDI score. The smaller the value score of FAD then will the greater the value of BDI. The worse the function of the family will be more severe levels of depression experienced by the sample in this study.
\end{abstract}

Conclusion: We found there was a significant weak negative correlation between family function and depression in palliative patients at Sanglah Hospital Denpasar.

Keywords: Palliative Care, Depression, Psychiatric Status Rating Scales

\section{Introduction}

The terminal disease illustrates a patient's health condition that cannot be recovered, so that this group of patients can be given a therapeutic approach known as palliative care. The palliative approach describes a therapeutic process aimed at reducing pain and discomfort experienced by patients due to an illness, without overcoming the disease and improving the quality of life of patients and families of patients who experience life-threatening illnesses through prevention and reducing the misery experienced. ${ }^{1}$

Palliative care is a patient care approach that aims to improve the quality of life of patients and their families when patients experience terminal illness that is life threatening. ${ }^{2,3}$ This is achieved through prevention and reduction of the sufferings or pain experienced by the patient as well as the patient's psychosocial and spiritual condition.

Depressive disorders are often found in the service of palliative patients. An estimated $15 \%$ of palliative patients meet the major depressive disorder criteria and many patients show symptoms of depression. This disorder has a negative impact on the physical condition of patients with severe illness. Typical manifestations that indicate the need for assessment related to depression include feelings of low feelings, crying, and persistent stress, loss of interest or happiness from daily activities, withdrawal from the patient's social sphere, feelings of hopelessness, resignation, helplessness, or feelings of guilt, thoughts, plans or attempted suicide, including requests to doctors to help kill themselves, or euthanasia. ${ }^{4}$

One aspect of patient management that has been shown to have meaningful results is the role of the family in the patient's therapy process. ${ }^{5,6}$ In the concept of palliative patient management, the family is the core of patient therapy. Family meetings have been shown to be meaningful in improving the quality of patient care, and ultimately, the patient's final outcome. ${ }^{6}$ 


\section{Patients and Methods}

This study is a cross-sectional, observational analytic study. The calculation used to determine the sample size required for the cross-sectional study showed 32 samples. The subject selection employed consecutive sampling method.

Questionnaires were completed and then returned to the researcher. Depression levels are measured using the Beck's Depression Inventory (BDI) questionnaire. This measuring instrument has 21 items that measure physical, cognitive, and emotional aspects. Subjects will choose what is felt during palliative care and then put in a score that has a range from 0 to 3.

The questionnaire contained a post-informed consent sheet, a BDI questionnaire and a Family Function Scale known as a Family Assessment Device (FAD). Respondents who have given their written approval then complete the questionnaire.

The total score will indicate the subject's depression level. Beck Depression Inventory has a maximum value of 63. Family function is measured by the Family Assessment Device (FAD). This instrument consists of seven subscales - problem solving, communication, roles, sense of responsibility, sense of involvement, control of behavior, and general functions. The questionnaire consists from positive and negative sentences, and for negative sentences, the scores given are reversed, which is $4-1$. The scores on each scale are summed and divided by the number of questions to get an average result. The mean values 1-2 indicate good family functioning; a value of close to 3 leads to poor family function; while value 4 indicates poor family function. This research has obtained ethical eligibility from Sanglah General Hospital Denpasar.

\section{Results}

Respondent characteristic data obtained from 32 samples undergoing palliative care at Sanglah Hospital Denpasar can be seen in Table 1. The function of the family in this study was assessed using the FAD questionnaire seen also in Table 2.

Pearson's correlation test found a significant negative correlation between the FAD score and BDI score $(r=-0.269$; $\mathrm{p}=0.037$ ). This means that the smaller the FAD score, the greater the BDI value. A smaller FAD score means worse family function, and a greater BDI score reflects a more severe level of depression. The worse the functioning of the family, the worse the level of depression experienced by the sample in this study.

Family function's relationship with depression in the study is presented in Table 3. The subjects who had lower family function tend to more severe depression level (55.6\%). A significant relationship was found between family function and depression in palliative patients at Sanglah Hospital Denpasar $(\mathrm{p}=0.047)$.
Table 1. Subject Characteristics

\begin{tabular}{lc}
\hline Characteristics & $\mathrm{n}=32$ \\
\hline Age (mean \pm SD) & $46.78 \pm 5.09$ \\
Gender, $\mathrm{n}(\%)$ & \\
Male & $17(53.1)$ \\
Girl & $15(46.9)$ \\
Marital status, $\mathrm{n}(\%)$ & \\
Married & $31(96.9)$ \\
Single & $1(3.1)$ \\
Education level, $\mathrm{n}(\%)$ & \\
No school & $3(9.4)$ \\
Elementary school & $5(15.6)$ \\
Middle school & $7(21.9)$ \\
High school & $12(37.5)$ \\
Bachelor & $5(15.6)$ \\
Depression rate, $\mathrm{n}(\%)$ & \\
Mild-moderate & $22(68.8)$ \\
Severe & $10(31.3)$ \\
\hline
\end{tabular}

Table 2. Description of the family function

\begin{tabular}{lccc}
\hline \multicolumn{1}{c}{ Variables } & Scores & Frequency & Percentage \\
\hline Family functions & & & \\
$\quad$ Low & $109-131$ & 9 & 28.1 \\
Moderate & $132-161$ & 19 & 59.4 \\
$\quad$ Severe & $162-188$ & 4 & 12.5 \\
\hline Communication & & & \\
domains & $16-17$ & 8 & 25 \\
$\quad$ Low & $18-19$ & 20 & 62.5 \\
$\quad$ Moderate & $21-23$ & 4 & 12.5 \\
$\quad$ High & & & \\
\hline Role domains & & & \\
Low & $16-17$ & 7 & 21.9 \\
$\quad$ Moderate & $18-23$ & 19 & 59.4 \\
$\quad$ High & $24-28$ & 6 & 18.8 \\
\hline Affective & & & \\
(responsiveness) & $10-12$ & 11 & 34.4 \\
$\quad$ Low & $13-17$ & 16 & 50 \\
$\quad$ Moderate & $18-20$ & 5 & 15.6 \\
$\quad$ High & & & \\
\hline Affective engagement & & & \\
Low & $9-13$ & 10 & 31.3 \\
Moderate & $14-18$ & 18 & 56.3 \\
High & $19-20$ & 4 & 12.5 \\
\hline Behavioral control & & & 31.3 \\
Low & $16-20$ & 10 & 56.3 \\
Moderate & $21-27$ & 18 & \\
High & $28-32$ & 4 & \\
\hline
\end{tabular}

Table 3. Relationship of family function to depression

\begin{tabular}{lccc}
\hline \multirow{2}{*}{ Family Function } & \multicolumn{2}{c}{ Depression severity } & \multirow{2}{*}{ p } \\
\cline { 2 - 3 } & Mild-moderate & Severe & \\
\hline Low & $4(44.4)$ & $5(55.6)$ & \\
Moderate & $15(78.9)$ & $4(21.1)$ & 0.047 \\
High & $3(75)$ & $1(25)$ & \\
\hline
\end{tabular}

\section{Discussion}

Depression is a psychiatric disorder characterized by sadness and loss of interest from activities that are usually carried out persistently and persist for at least two weeks. Depressed patients can experience loss of energy, changes in appetite, changes in sleep patterns (reduced or excessive), anxiety, 
decreased concentration power, inability to make decisions, feelings of uncertainty, feelings of worthlessness, feelings of guilt or no hope, and thoughts of self-injury alone or suicide. ${ }^{2,3}$

Psychiatric Association in America, through the Diagnostic Statistical Manual of Mental Disorders, Fifth Edition (DSM-5) categorizes depressive disorders as disorders of mood dysregulation, major depressive disorders (including major depressive episodes), persistent depressive disorders (dysthymia), dysphoric disorders pre-menstruation, and depressive disorders due to medical conditions. ${ }^{3}$ In addition, depressive disorders can be further categorized by the presence of other specifications such as post-partum onset, seasonal patterns, melancholy characteristics, psychotic characteristics according to mood or mood, severe anxiety, and catatonia. One typical finding that indicates depression is feelings of sadness, emptiness, or easily saturated behavior, along with somatic and cognitive changes that affect a person's capacity to function meaningfully. ${ }^{2,3}$

In this study found the characteristics of age with an average age of 46 years, more in men by $53.1 \%$, after marriage by $96.9 \%$, high school education level of $37.5 \%$ of the sample with a moderate prevalence of depression which is $68.8 \% .^{7,8}$ The more samples that have family functions are at a moderate level, and the domain of the function of the studied families are also more at a moderate level both in terms of communication, roles, affective responsiveness, affective involvement, behavior control. ${ }^{9}$ The role that is lacking in the family has a negative effect on individuals who are in the family in terms of physical and emotional. This has the potential to provide a feeling of insecurity, a sense of uncertainty about the family, a sense of abandonment, and feeling alone which can then be a trigger for the occurrence of depression in individuals. ${ }^{10}$ Family function is high then, severe depression becomes $25 \%$ and moderate depression as much as $75 \%$. Whereas if you're a family function, we will get depressed by $21.1 \%$ and moderate depression by $78.9 \%$. This indicates that if the family functions better, it will decrease if severe depression.

\section{Conclusion}

Based on the results of the research above, it can be concluded that there was a significant weak negative correlation between family function and depression in palliative patients at Sanglah Hospital Denpasar. This means that the lower the family function score, the higher the depression score.

\section{Acknowledgment}

The authors report no conflict of interests.

\section{References}

1. Hawley P. Barriers to Access to Palliative Care. Palliat Care. 2017;10:1178224216688887. doi:10.1177/1178224216688887

2. Kanter JW, Busch AM, Weeks CE, Landes SJ. The nature of clinical depression: symptoms, syndromes, and behavior analysis. Behav Anal. 2008;31(1):1-21. doi:10.1007/BF03392158

3. National Institutes of Health (US); Biological Sciences Curriculum Study. NIH Curriculum Supplement Series [Internet]. Bethesda (MD): National Institutes of Health (US); 2007. Information about Mental Illness and the Brain. Available from: https://www.ncbi.nlm.nih.gov/books/NBK20369/

4. Rayner L, Price A, Hotopf M, Higginson IJ. The development of evidence-based European guidelines on the management of depression in palliative cancer care. Eur J Cancer. 2011;47(5):70212. doi: 10.1016/j.ejca.2010.11.027.

5. Lloyd-Williams M, Shiels C, Ellis J, Abba K, Gaynor E, Wilson K, Dowrick C. Pilot randomised controlled trial of focused narrative intervention for moderate to severe depression in palliative care patients: DISCERN trial. Palliat Med. 2018;32(1):206-215. doi: $10.1177 / 0269216317711322$.

6. Hudson P, Quinn K, O'Hanlon B, Aranda S. Family meetings in palliative care: Multidisciplinary clinical practice guidelines. BMC Palliat Care. 2008;7:12. doi: 10.1186/1472-684X-7-12.

7. Krug S, Wittchen HU, Lieb R, Beesdo-Baum K, Knappe S. Family functioning mediates the association between parental depression and low self-esteem in adolescents. J Affect Disord. 2016;203:184189. doi: 10.1016/j.jad.2016.06.008

8. Hasegawa T, Okuyama T, Uchida M, Aiki S, Imai F, Nishioka et al. Depressive symptoms during the first month of chemotherapy and survival in patients with hematological malignancies: A prospective cohort study. Psychooncology. 2019;28(8):1687-1694. doi: 10.1002/pon.5143.

9. Lewandowski AS, Palermo TM, Stinson J, Handley S, Chambers CT. Systematic review of family functioning in families of children and adolescents with chronic pain. J Pain. 2010;11(11):1027-1038. doi:10.1016/j.jpain.2010.04.005

10. Tshomo Y, Chaimongkol N. Prevalence of depression and its associated factors among persons with chronic medical illness in Bhutan. Arch Psychiatr Nurs. 2019;33(4):347-351. doi: 10.1016/j.apnu.2019.02.002. 